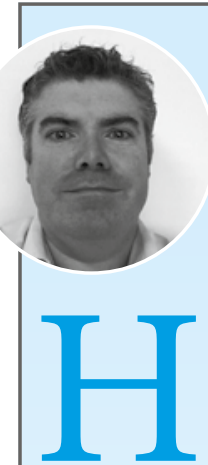
Pensions tax - BDA needs you By Phil McEvoy, BDA Head of Pensions the Inspector to joyfully advertise the fact that 'tax doesn't have to be taxing.'

Hector, retired in 2001, would be spinning in his cartoon grave if he ever came up against the current system for taxing pension savings in the UK.

It is important to note that saving into a pension is generally a very positive and tax efficient way to make provision for your old age. It is also worth noting that the NHS Pension Scheme remains one of the best vehicles to save for retirement, offering guaranteed incomes and generous contributions from government.

However, government places limits on the tax efficiency of pension saving through the Annual Allowance and Lifetime Allowance. Since 2010, reductions to these allowances have left many higher earning and longer serving dentists being presented with tax bills that have not been anticipated and that they cannot understand.

In response to receiving these tax charges, many dentists have sought to reduce their NHS pension entitlement by taking early retirement, by opting out of the pension scheme or by undertaking less NHS work.

We raised concerns about the impact of pensions tax back in 2017 and have lobbied governments since then. Our argument is that the NHS Pension Schemes should be flexible enough to allow members to pay less, in order to build up lower NHS pensions and thereby avoid tax charges. This would mean that affected dentists do not need to seek early retirement or reduce NHS work; but that they are able to build up pensions at a level that do not attract extra tax charges.

The Department of Health and Social Care have launched consultations indicating that such flexibility could be introduced soon. However, they have indicated that they require evidence in order to be convinced that pensions tax is causing problems with the provision of NHS dentistry, and that pension flexibilities should be extended to dentists.

We have written to the Secretary of State for Health and Social Care making the initial case for dentists and stating that pension flexibility should be available to everyone. However, we will still need to provide evidence in response to the consultations.

Our survey of dentists can be accessed at https://www.smartsurvey.co.uk/s/ bdapensionstax/ Your views on this matter can help us best make the case for pension flexibility for dentists. The survey is scheduled to close on 27 September in order to allow us to use results in our response to the Government consultation.

In the meantime, members are reminded to proactively access NHS pension information from your pension scheme. You can view the BDA's guidance on the current tax system at www.bda.org/about-the-bda/campaigns/pay/ Pages/Pensions-tax.aspx
BDA calls on Scottish Government to implement recommended pay uplifts

BDA Scotland is calling on the Scottish Government to accept the recommendation in the 47th report of the Review Body on Doctors' and Dentists' Remuneration (DDRB) of an above inflation 2.5\% net uplift for general dental practitioners.

This follows the announcement in July that the UK Government has accepted the $2.5 \%$ recommendation for dentists in England.

The BDA is also calling on the Scottish Government to award at least 3\% for expenses, introduce the overall pay uplifts as soon as possible and backdate them to April 2019.

David McColl, Chair of the Scottish Dental Practice Committee, said: 'While we were disappointed in the delay in publishing the DDRB report, the Scottish Government now needs to follow its Westminster counterpart and announce that it accepts the DDRB recommendation.

'To avoid significant recruitment and retention problems, an above-inflation increase is now the very least Ministers can do if they want NHS dentistry in Scotland to remain sustainable.

'Implementing DDRB recommendations in full won't reverse a $30 \%$ collapse in real incomes, but it will send a clear signal that we have finally turned a corner on a pay policy that has put increasing pressure on NHS services.'

\title{
Health Committee inquiry in NHS dentistry welcomed
}

The BDA has welcomed news that the House of Commons Health and Social Care Committee has announced an inquiry into dental services.

The BDA has been working to expose the deficiencies in dental access, funding and strategy and raise the profile of dentistry in Parliament. The inquiry follows repeated conversations with both the Chair Dr Sarah Wollaston and other members of the
Committee. News follows the BDA securing an inquiry and a hearing from the Public Accounts Committee, which has already delivered a U-turn on the government's controversial 'fines first' approach to NHS penalty charges.

BDA Chair Mick Armstrong: 'We have pulled out all the stops to push NHS dentistry up the political agenda. Now the Health and Social Care Committee has a chance to shine a light on a system that is failing patients and practitioners across England.

'The Government has yet to wake up to the full scale of the crisis in NHS dental services. But on contracts and funding, on access and recruitment, we will use this inquiry as another chance to make the point that problems made in Westminster can only be fixed in Westminster.' 